\title{
Editorial
}

\section{Some important distinctions in place branding}

'Brand' is a difficult word. The problem of defining it has spawned thousands of papers and articles in the marketing field, and it is still widely misunderstood.

'Brand' is one of those jargon words like 'trauma' and 'phobia' which serve for years, performing a humble descriptive role within their own specialist sector. Then, for some reason, the specialist sector suddenly becomes the focus of public attention, and there is a mad rush for the jargon. Words get appropriated, first by journalists, then by the population at large and finally by politicians, and used for all the wrong purposes in all the wrong places. The words quickly lose their edge and are eventually discarded because they do not seem to work properly any more.

We may now be seeing this happen to 'brand'. Now that Madonna and Pavarotti are brands and Greenpeace is a brand, US foreign policy, the European Union and NATO are brands, the word is perilously close to becoming a synonym for 'thing'. Thanks to the wide success of a slew of anti-global, anti-corporate, anti-this and anti-that books — Naomi Klein's 'No Logo', Alissa Quart's 'Branded', Eric Schlosser's 'Fast Food Nation', George Monbiot's 'Captive State' and many more besides - 'brand' is quickly becoming synonymous with 'bad thing'.

The linking of this ever-popular theme to the wave of vague but keenly felt support for the anti-global, anti-corporate and anti-empire movements was a stroke of publishing genius, and has probably blackened the word 'brand' for generations to come. This is a pity, because it risks blinding people to the real economic and social values which the discipline of branding can bring if responsibly and imaginatively applied.

So it is particularly important that, before entering into conversations about the branding of places, there is clarity about which particular interpretation of the word is intended. Far too many discussions about place branding go awry because of a failure to establish a common understanding of the word before starting, and this sets up a cognitive dissonance between the participants which can go unobserved for a very long time before the argument breaks down in confusion or acrimony.

\section{THREE DEFINITIONS OF BRANDING}

The words 'brand' and 'branding' are used, broadly speaking, in three ways: a popular way, a simple way and an advanced way. (I will not attempt to consider here what the differences are between 'brand' and 'branding', as that question provides material enough for a paper on its own.)

The popular understanding of branding is the least precise: it is used as a vague conflation of several marketing disciplines, and often interchangeably with advertising, marketing, PR and sales promotion. It is believed to be a marketing buzzword which refers in a general way to all modern selling 
activities, and often has a connotation of something aggressive and malevolent, which descends directly from an older use of the term (eg 'branded as a traitor'), and ultimately to the original meaning of the word: a hot iron applied to livestock, permanently identifying the animal's ownership.

The simple understanding of branding is used by marketing services firms and their clients and refers to a designed visual identity - name, logo, slogan, corporate livery. It is the way in which the identity of the company, product or service is dressed, and thus recognised. In a subtle way, this dress is also understood to be a channel of communication; the style and content of the design implies something about the nature and personality of the product, and consequently its desired target audience.

The advanced definition of branding includes the simple definition but goes on to cover a wide area of corporate strategy, consumer and stakeholder motivation and behaviour, internal and external communications, ethics and purpose. Companies which espouse this understanding of branding use it to navigate through the complex web of relationships between the personality of the company, product or service - the brand itself - and the people who produce and deliver it, as well as the people who consume it or otherwise come into contact with it.

This understanding of brand also recognises that in marketplaces where the functional or physical attributes of companies and their products become less and less relevant, their intangible or brand-related qualities — the 'halo' of value and associations, lifestyle, desirability of the marque, the strength of the maker's reputation and the behaviour of the company's representatives become paramount.

Advanced brand theory therefore recognises that companies are unlikely to achieve a sustainable advantage in the marketplace unless both employers and employees - and ideally other stakeholders too - share some beliefs about the product or service and engage in a degree of consistent behaviour.

This advanced conception of branding in a company is a total approach to managing a business, with the brand providing the key to company strategy and corporate culture. According to this definition, the brand becomes a central organising function of the company, and may prove to be the company's most valuable asset.

The popular and simple ways in which the word is understood are based on a belief that branding is simply a technique or set of techniques, like 'advertising' or 'root canal surgery', and consequently can be defined both succinctly and comprehensively. The advanced definition, on the other hand, considers branding to be a field of theory and practice, like 'business' or 'medicine', which can of course be briefly described but not exhaustively defined except through a study of its practice and literature, which, while not as broad as those of business or medicine, includes many hundreds of works.

\section{ADVANCED BRANDING AND ITS APPLICATION TO PLACES}

Much of the animosity shown towards the concept of place branding arises directly from the popular or simple understanding of the word 'brand', leading to an assumption that the practitioners and supporters of the discipline wish to brand nations like cattle - in other words, to slap on an attractive logo and a catchy slogan, and market the thing as if it were nothing much more than a product in the supermarket.

This is an animosity with which the 
writer entirely sympathises: the idea that simply providing a place with a new graphic device and a new catchphrase can do anything to change its fortunes (other than by wasting its money) is patently absurd.

When, on the other hand, the best lessons, techniques and observations from advanced branding are intelligently, responsibly and imaginatively applied to places, the consequences are fascinating, far-reaching and potentially world-changing.

Not only are people often confused about what branding is: they are also confused about what is being branded. There is a lack of clarity about the difference between place branding and the promotion of the nation's individual assets or 'products', such as tourism, inward investment, culture and exports. 'Destination branding', a term often used to indicate a modern form of tourism promotion, is frequently conflated with nation branding, but this is misleading, as Hugh Davidson points out in his book review in this issue. Tourism is just one component of the city, nation or region (readers may recall my use of the 'nation-branding hexagon' to illustrate this relationship), and, unlike the nation as a whole, is a 'product' which needs to be 'sold' in the global marketplace. In this context, simple branding is not only possible but also necessary, and the whole panoply of visual identity, slogans, design and advertising plays a critical role in selling the product.

Components of the place can be promoted, even sold, but the nation, city or region cannot. This is partly because, almost by definition, the nation is unlikely to have a single target market or a single offering, and in such conditions promotion becomes difficult and rather pointless. Amine and Chao's paper on Taiwan in this issue presents interesting food for thought on this subject -
Taiwan being one example of a country which has attempted to promote itself as a whole, using conventional promotional techniques. The only single message which an entity as complex and diverse as a country could possibly settle on as representing its 'pitch' to the world would be so vague and so bland as to render any expenditure on broadcasting the message a waste of resources. People, as a rule, are only prepared to give their attention to commercial messages which are inherently interesting, and no amount of expenditure on media or creativity can force people to pay attention to a message which is vague, bland or general. Hence the dismal nature of much 'corporate' advertising, which usually achieves little more for the corporation than reassuring shareholders of its prominence.

For the same reason, corporations which produce a number of different products, like Procter \& Gamble or Unilever, tend not to promote themselves directly, but rely on good governance and brand portfolio management to build their corporate brands. Countries, regions and cities are likewise best promoted indirectly by a harmonised and strategically informed approach to the promotion of their 'products' and 'sub-brands', and their overall reputations built by their actions and behaviour (which are guided, of course, by the same strategy).

The question which all effective promotional activity must address at some level is the consumer's eternal 'what's in it for me?'. When we are talking about a country, a region or a city, the question has little or no meaning.

But whether or not countries, cities and regions can be promoted, they certainly do have brands, and those brands certainly do affect the views, decisions and behaviour of their friends, 
enemies, allies, visitors, investors and consumers. The application of advanced branding in this context is much more an attempt to manage the 'reputational assets' of the place than sell it in the global marketplace: in other words, to do whatever is possible to ensure that the country's reputation is a fair, balanced and useful reflection of its real assets, competencies and offerings, and not merely an outdated or unjustly biased cliché, informed by long-past events or ignorant assumptions.

\section{THE SIGNIFICANCE OF PLACE BRANDING}

Since the most commonly held understanding of branding outside sophisticated marketing departments tends to be the popular or, at best, the simple, it is hardly surprising that policy makers are reluctant to accept that this approach can have anything of truly central importance to their work.

Yet there is undoubtedly a growing acceptance in public affairs that a familiarity with the techniques of commercial marketing is increasingly relevant. That ministries of foreign affairs and their foreign services must practise something called 'public diplomacy' is now commonplace; likewise the fact that public affairs has become an international affair, and that investment promotion and tourist promotion must be as sophisticated as the most sophisticated commercial marketing, since both are competing for consumer mindshare in the same space.

But the debate never seems to go beyond the not-very-challenging truism that some learnings from the private sector can bring benefits to the way in which places are marketed: a bit of PR or media training can sharpen up diplomacy in the 'media age'; a knowledge of internet marketing and online media planning can make tourist boards more competitive; some attractive design can help investment promotion agencies in their work; and so forth.

If the usefulness of modern commercial practice and theory to statecraft really did amount to this and nothing more, it would be difficult to justify the existence of this journal, or indeed to explain the excitement around the emergence of a field called place branding.

No, the reason why the convergence of advanced brand theory and statecraft is truly epoch-making is because branding is, potentially, a new paradigm for how places should be run in the future.

A globalised world is a marketplace where country has to compete with country - and region with region, city with city - for its share of attention, of reputation, of spend, of goodwill, of trust. That places should look to the disciplines of the marketplace for inspiration about how to prosper in this world is entirely logical.

The objection that the commercial model is mainly associated with profits rather than people does not stand up to scrutiny. Branding in its advanced form is primarily about people, purpose and reputation, not about money - although there is little question that organisations which are clear about their brand values and brand strategies ultimately stand a better chance of sustainable profitability than those which are not.

Flexibility is the essence of modern brand theory: it has a unique ability to equate 'soft', human issues with 'hard' financial and organisational ones and resolve them humanely and intelligently into a functioning and compassionate whole. It reconciles the needs of the organisation and the forces of the marketplace with the 'human capital' which is the raw material of both. In the commercial sector, enlightened brand strategy embraces creativity and human 
resources with administration and finance; so, in the public sector, it comfortably embraces culture and society with economics and politics.

\section{WHY THE TIME FOR PLACE BRANDING HAS COME}

Big changes in the social and political fabric of modern society make the more 'public-oriented' approach of place branding a necessity in the 21 st century. This is not a question of governments 'playing to the gallery' or a strategy for legitimising state propaganda, but simply a growing acknowledgment of the influence of peoples on international affairs. As I mentioned in my editorial to the first issue of Place Branding, a rough distinction between place branding and propaganda might be that "propaganda is the deliberate use of manipulated public opinion as a tool for achieving a political end; place branding is the consequence of a realisation that public opinion is an essential component of achieving a political end'.

Just a few of the conditions which now make a brand-oriented approach to statecraft not merely desirable but necessary are as follows:

- The spread of democracy and democratic-type governance in many parts of the world and an increasing tendency towards transparency of government and open relationships between state players, as well as a growing interest and awareness of international affairs among publics, drives the need for a more 'public-aware' approach to politics, diplomacy and international relations.

- The growing power of the international media, driven by a more informed and news-hungry audience and more influential non-governmental organisations, makes it harder for states to persist in secretive, unethical or authoritarian behaviour.

- The falling cost of international travel, the rising spending power of a growing international middle class and its constant search for unfamiliar experiences compel more and more places to market themselves as tourist destinations; at the same time, the threat of 'product parity' among such destinations makes a clear, distinguishing and economically sustainable brand strategy essential so that they can compete effectively in the international marketplace.

- An ever more tightly linked global economic system and a (currently) rather scarce pool of international investors being chased by a growing number of industrial and service locations applies similar pressures to the business of foreign direct investment promotion; again, the tendency towards parity between the offerings and the need for a competitive strategy which is sustainable in the long term against the threat of highly mobile global capital drives places towards an ever more sophisticated and brand-led approach to developing, managing, positioning and promoting themselves in the marketplace.

- A range of consumer products sourced from an ever wider pool of countries increases the need to build trust in both company and country of origin; at the same time, a growing interest, reflected in the international media, in the ethical and ecological credentials of manufacturers and service providers creates a situation where it is ever more critical for places to pursue a long-term strategy for building and managing a positive country-of-origin effect.

- For poor and developing places, the 
intense competition for international funds, technology and skills transfer, inward investment, export markets and trade makes a clear positioning, a well-defined sense of national economic, social and political purpose and a degree of influence over national reputation more and more essential.

- Countries, regions and cities are also competing more intensely and more widely than ever before for talented immigrants, whether these are foreign nationals in search of ideal social, cultural, fiscal and living conditions, or returning members of the diaspora looking to reinvest in their home country. Again, a clear positioning, a believable and attainable set of promises in these areas and a well-maintained and well-deserved reputation become essential attributes of the competitive nation-state.

- A growing demand on the part of consumers for an ever wider, richer and more diverse cultural diet, enabled and stimulated by the rapid growth of low-cost global digital and communications media, means that the global marketplace is open as never before for places with unusual and distinctive traditional or invented cultural products to "punch above their weight' in world affairs, and use their culture to communicate more of the real richness of their society to ever more distant audiences.

- The currently depressed popularity of American culture, policies, products and services will create a vacuum in the global marketplace for clearly positioned and consistently presented places to build real competitive advantage.

The list could continue for page after page. The driver of the new paradigm is simply globalisation: a series of regional marketplaces (and by marketplaces I mean not merely markets for products or funds, but for ideas, for influence, for culture, for reputation, for trust and for attention) which are rapidly fusing into a single, global community. Here, only those global players - be they countries, cities, regions, corporations, organisations, religions, NGOs, charities, political parties or individuals - with the ability to approach a wide and diverse global marketplace with a clear, credible, appealing, distinctive and thoroughly planned vision, identity and strategy will survive and prosper.

Some claim that such a situation unfairly favours places with the funds to promote themselves more vigorously than others, but this view derives from the popular view of brands, where branding is confused with advertising and other traditional forms of paid-for media promotion. A powerful and imaginative strategy which is more the product of intellectual than of financial capital, as in the commercial marketplace, may well prove a greater asset than huge amounts of money used to thrust uninspiring messages on to an unwilling audience.

For places to achieve the benefits which the better-run companies derive from branding, the whole edifice of statecraft needs to be jacked up and underpinned with the learnings and techniques which commerce, over the last century and more, has acquired. Much of what has served so well to build shareholder value can, with care, build citizen value too; and citizen value is the keynote of governance in the modern world.

The underlying theme of this publication is that branding, if it is to serve its real purpose in the world, is not something you add on top: it is something that goes underneath.

Simon Anholt Managing Editor 